\title{
Kultur Pengasuhan Keluarga terhadap Perkembangan Moral Anak Usia Dini
}

\author{
Tsali Tsatul Mukarromah ${ }^{\bowtie}$ 1, Ruli Hafidah², Novita Eka Nurjanah ${ }^{3}$ \\ Pendidikan Guru Pendidikan Anak Usia Dini, Universitas Sebelas Maret \\ DOI: $10.31004 /$ obsesi.v5i1.550
}

\begin{abstract}
Abstrak
Moral dapat dilihat sebagai tata perilaku kebiasaaan yang sesuai lingkungan tinggal yang berhubungan mengenai perilaku baik ataupun buruk. Perkembangan moral anak tidak lepas dari kontribusi orang tua. Kultur pengsuhan keluarga menjadi salah satu hal dari kontribusi tersebut. Tujuan dari dilakukannya penelitian ini adalah untuk menganalisis kultur pengasuhan keluarga terhadap perkembangan moral anak usia dini. Metode yang digunakan dalam penelitian ini adalah metode kajian pustaka yang dilakukan dengan mengumpulkan dan menelaah sumber-sumber ilmiah yang kemudian dihubungkan dengan penelitian untuk memecahkan masalah. Hasil penelitian menunjukan bahwa gaya pengasuhan dan pengasuhan dari keluarga khususnya orang tua memiliki keterkaitan dengan perkembangan moral anak, keterkaitan berupa dampak masing-masing gaya pengasuhan meliputi gaya pengasuhan demokratis, gaya pengasuhan otoriter, dan gaya pengasuhan permisif yang diterapkan dalam keluarga yang kemudian berkontribusi pada perkembangan anak di masa selanjutnya.
\end{abstract}

Kata Kunci: pengasuhan keluarga; moral; anak usia dini.

\begin{abstract}
Moral can be seen as a way of life in accordance with the environment associated with good or bad habits. Moral development of children can not be separated from the contribution of parents. The culture of family care becomes one of the things that is recognized. The purpose of this study was to analyze the caregivers' family culture on the moral development of early childhood. The method used in this research was a literature review method which is done by collecting and studying scientific sources which are then linked to research to solve problems. The results showed that parenting style and parenting style of a particular family of parents had a relationship with the moral development of children, the relationship forming each parenting style which includes parenting style, authoritarian parenting style, and permissive parenting style of children in the future.
\end{abstract}

Keywords: family parenting; moral; early childhood.

Copyright (c) 2020 Tsali Tsatul Mukarromah, Ruli Hafidah, Novita Eka Nurjanah

$\triangle$ Corresponding author :

Email Address : tsalisa_13@student.uns.ac.id (Ngawi, Jawa Timur, Indonesia)

Received 23 May 2020, Accepted 11 June 2020, Published 28 June 2020 


\section{PENDAHULUAN}

Pendidikan anak usia dini adalah salah satu upaya perubahan dan pemajuan yang dilakukan dengan membimbing, mengasuh, dan menstimulasi anak usia sejak lahir hingga enam tahun. Pada usia tersebut anak memasuki periode sensitif yaitu masa kritis yang menghasilkan perubahan ireversibel dalam fungsi otak yang tidak dapat diperbaiki ketika dewasa (Knudsen, 2004). Sehingga, anak perlu mendapat stimulasi dari orang tua dan lingkunganya agar dapat tumbuh dan berkembang secara optimal.

Pertumbuhan dan perkembangan berjalan secara beriringan. Perkembangan merupakan perubahan-perubahan yang terjadi sepanjang masa kehidupan. Perkembangan tersebut mencakup seluruh aspek perkembangan yang dalam (Permendikbud No. 137, 2014) mencakup aspek fisik motorik, aspek kognitif, aspek bahasa, aspek sosial emosi, aspek nilai agama dan moral, serta aspek seni. Setiap aspek tersebut perlu dikembangkan dengan maksimal, karena antara aspek yang satu dengan yang lain saling terkait dan saling mempengaruhi termasuk aspek perkembangan moral.

Moral dapat diartikan sebagai tata perilaku kebiasaaan sesuai norma masyarakat atau lingkungan yang berhubungan dengan baik ataupun buruk. Dalam (Ellemers, van der Toorn, Paunov, \& van Leeuwen, 2019) Haidt dkk., menyatakan moralitas yaitu menunjukkan apa jalan yang "benar" dan "salah" dalam berperilaku, misalnya, ketika seseorang harus adil dan tidak adil. Perkembangan moral pada anak sendiri belum dapat dipastikan seberapa awal munculnya akan tetapi ada beberapa pendapat terkait awal adanya perkembangan moral, seperti yang disebutkan dalam (Turiel, 2018) perkembangan moral sudah ada sejak masa kana-kanak awal. Kemudian, dalam (Molchanov, 2013) menyatakan jika perkembangan moral anak ada pada masa kana-kanak tengah. Perkembangan moral dalam (Jambon \& Smetana, 2015) disebutkan bahwa asal perkembangan moral diasumsikan berangkat dari teori sosial dan teori kognitif. Teori sosial memandang konsep perkembangan moral merujuk pada hal-hal terkait internalisasi dan kepatuhan anak terhadap orang dewasa serta aturan yang mengikat lingkungan masyarakat, peran emosi tetap mempengaruhi dalam proses tersebut. Sementara, teori kognitif memandang pendekatan perkembangan moral fokus pada pengembangan penilaian moral anak-anak itu sendiri. Pendekatan tersebut maksudnya anak aktif dalam perkembanganya sendiri dan membangun pengetahuan moral melalui interaksi timbal balik dengan lingkungan atau konstrutif. Proses perkembangan moral tidak hanya terkait dengan internalisasi nilai-nilai dan standar eksternal tetapi tetap merupakan proses konstruktif yang mengarah pada perubahan kualitatif dalam pemikiran anak-anak tentang benar dan salah. Pada intinya perkembangan moral sudah ada pada masa kanak-kanak beriringan dengan aspek perkembangan anak yang lainya seperti kognitif maupun sosial emosionalnya yang dapat dipengaruhi oleh lingkungan.

Masa kanak-kanak menurut tahapan teori Kohlberg dalam Campbell, Cavico, Pellet, \& Mujtaba, (2010) memasuki tahapan perkembangan moral pra-konvensional dimana penalaran moral anak-anak bersifat eksternal yang dapat diartikan dikendalikan oleh lingkungkan luar atau orang lain, yaitu prilaku mereka terikat oleh adanya imbalan dan hukuman. Tahap pra-konvensional meliputi dua tahapan, yaitu tahap pertama (kepatuhan dan hukuman) dan tahap kedua (tujuan individu dan pertukaran). Pada tahap kepatuhan dan hukuman, penalaran moral anak-anak didasarkan atas hukuman dan ketaatan individu karena orang lain menuntut mereka untuk taat, dengan kata lain mereka berusahaa untuk mentaati aturan untuk menghindari hukuman. Sementara, pada tahap tujuan individu dan pertukaran, penalaran moral anak-anak didasarkan atas imbalan dan kepentingan sendiri. Anak-anak akan taat apabila mereka mengangap ketaatan adalah hal yang benar dan hal yang benar membawa mereka pada imbalan, dengan kata lain mereka mentaati aturan ketika mereka merasa itu adalah hal terbaik. 
Lingkungan luar yang mengendalikan penalaran moral anak-anak salah satunya adalah lingkungan keluarga. Peran keluarga khususnya orang tua menjadi salah satu faktor penting dalam perkembangan moral anak usia dini. Keluarga sebagai lingkungan pendidikan pertama bagi anak dengan orang tua adalah sebagai gurunya. Lingkungan keluarga ini juga memiliki kontribusi dalam perkembangan moral anak, dimana orang tua berperan dalam menginternalisasikan nilai-nilai moral pada anak. Seperti studi yang telah ada sebelumnya dalam Volling, Mahoney, \& Rauer (2009) menyatakan di dalam keluarga anak-anak mengembangkan moral dengan adanya perilaku prososial awal yang ditunjukkan kepada orang lain ataupun lingkungannya.

Setiap keluarga memiliki kulturnya masing-masing. Di dalam keluarga terdapat pola-pola hubungan interaksi yang menjadikan keluarga satu dengan yang lain itu berbeda. Selain itu latar belakang setiap keluarga juga mempengaruhi kultur dalam sebuah keluarga seperti aturan-aturan yang terdapat di dalam keluarga, pola kebiasaan keluarga, hingga kultur pengasuhan. Dalam kultur pengasuhan didalamnya terdapat gaya pengasuhan, Baumrind (1971) dalam (Bibi dkk., 2013) menyebutkan gaya pengasuhan keluarga meliputi pengasuhan otoritatif (authoritative), otoriter (authoritarian), dan permisif dengan konsep tanggapan dan persyaratan (permissive with these concepts of responsiveness and demandingness). Selanjutnya, pengasuhan orang tua dalam menanamkan sebuah sikap kepatuhan maupun kedisiplinan terhadap anak dengan menggunakan cara yang keras maupun tidak. Dalam Grusec, Goodnow, \& Kuczynski (2000) menunjukan bahwa pengaruh orang tua terhadap perolehan nilai-nilai moral anak-anak tergantung pada beberapa faktor termasuk karakteristik anak-anak, upaya sosialisasi orang tua dengan anak-anak mereka, sejarah hubungan keluarga yang lebih luas, dan tujuan praktik sosialisasi tertentu yang dilakukan orang tua karena alasan dan kondisi situasi tertentu. Hal-hal tersebut memiliki kontribusi pada perkembangan moral anak dimana mereka mulai belajar mengembangkan moralnya sejak dini, kontribusi yang ada dapat berupa hal yang baik maupun sebaliknya. Berdasarkan penelitian-penelitian yang telah ada sebelumnya kultur pengasuhan keluarga memiliki kontribusi terhadap perkembangan anak usia dini termasuk perkembangan moral anak.

Pembentukan moral yang baik perlu dilakukan sedini mungkin dengan cara yang tepat karena berpengaruh pada kehidupan anak selanjutnya. Nasution \& Maulana (2020) Ma'rifah, Suryantini, \& Mardiyana, (2018); Muin, (2015); Rachmawati \& Nurmawati (2014), menyebutkan pola asuh merupakan strategi orang tua terhadap anak yang terkait dengan sosialisasi, merawat, mendidik, membimbing, melindungi, pendisiplinan anak sebagai proses anak untuk belajar dalam bertingkah laku agar dapat diterima lingkungan sosial. Pengetahuan akan kultur pengasuhan yang tepat terhadap anak diperlukan agar orang tua dapat mempertimbangkan hal-hal yang terkait dengan mendidik anak agar perkembangan moral pada anak dapat berkembang dengan semestinya dan tentunya anak memiliki moral yang dapat diterima lingkungan sosialnya.

Lingkungan keluarga terutama orang tua memiliki peranan yang besar dalam perkembangan anak terkait dengan gaya pengasuhan dan pengasuhanya. Mengingat dampak tipe-tipe pengasuhan terhadap anak yang berbeda dari setiap orang tua menjadi sangat penting untuk mengetahui dan mempertimbangkan perbedaan-perbedaan tersebut. Misalnya, seseorang bisa membayangkan orangtua yang hangat (demokratis), dimana orang tua tidak terlalu ketat dan selalu memberi kesempatan kepada anak. Apakah dampak hubungan dari pengasuhan orang tua tersebut sama dengan bentuk-bentuk pengasuhan lainya. Pengetahuan mengenai jenis-jenis gaya pengasuhan dan dampaknya diharapkan dapat memberikan pandangan yang lebih baik tentang bagaimana mengasuh anak sehingga dapat meningkatkan pengembangan moral pada anak-anak. Berdasarkan pemaparan yang ada, peneliti tertarik melakukan penelitian yang membahas mengenai kultur pengasuhan keluarga terhadap perkembangan moral anak. 


\section{METODOLOGI}

Metode yang digunakan dalam penelitian ini menggunakan metode kepustakaan, kepustakaan atau kajian pustaka dalam suatu penelitian ilmiah merupakan salah satu bagian penting dari keseluruhan langkah-langkah metode penelitian. Wandi \& Mayar (2020) Sanusi (2016) mengartikan kajian putaka library research, sebagai kegiatan penelitian dengan mengumpulkan data-data atau berdasarkan karya tulis ilmiah yang berkaitan dengan obyek penelitian atau pengumpulan datanya bersifat kepustakaan, kemudian telaah dilaksanakan untuk memecahkan suatu masalah dan mendalam terhadap bahan-bahan pustaka yang relevan. Kajian pustaka menggunakan sumber pustaka yang ada untuk memperoleh data penelitian, sehingga dengan hal tersebut peneliti tidak perlu melakukan riset secara langsung.

Selanjutnya, ada tiga alasan mengapa peneliti melakukan penelitian kepustakaan, yaitu: 1) permasalahan dalam penelitian hanya dapat dijawab melalui penelitian kepustakaan; 2) kajian pustaka dibutuhkan sebagai salah satu tahap tersendiri, dimana studi pendahuluan diperlukan untuk memahami gejala baru yang sedang berkembang didalam masyarakat; 3) penelitian kepustakaan dapat di percaya hasilnya dalam menjawab permasalahan penelitian (Wandi \& Mayar, 2020). Analisis data kajian pustaka ini dilakukan dengan analisis isi (content analysis) atau penelitian yang bersifat pembahasan mendalam terhadap isi suatu informasi tertulis atau tercetak.

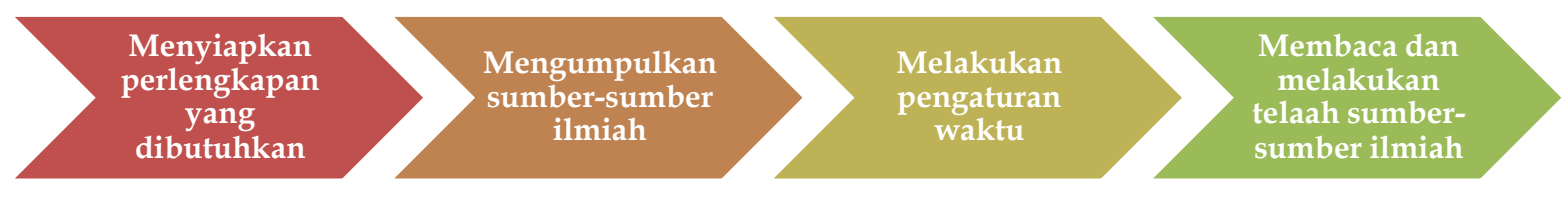

Gambar 1. Langkah-langkah penelitian kajian pustaka

Sebelum melakukan telaah sumber-sumber ilmiah, peneliti perlu mempersiapakan perlengkapan termasuk alat yang akan digunakan dalam penelitian, kemudian peneliti menentukan dan mengetahui secara pasti sumber ilmiah apa saja yang diperlukan dalam penelitian. Adapun sumber yang digunakan yaitu buku-buku teks, jurnal-jurnal ilmiah dan dokumen-dokumen (baik yang berbentuk cetak maupun elektronik) serta sumber-sumber data dan atau informasi lainnya yang dianggap relevan dengan penelitian atau kajian. Lalu, peneliti perlu melakukan pengaturan waktu dengan sebaik mungkin untuk mencapai tujuan penelitian. Setelah itu, peneliti dapat membaca dan menelaah sumber-sumber ilmiah atau pustaka tersebut. Hal-hal tersebut masih sejalan dengan langkah-langkah penelitian studi pustaka Zed (2008) (Nasution \& Maulana, 2020).

\section{HASIL DAN PEMBAHASAN}

\section{Gaya Pengasuhan Keluarga terhadap Perkembangan Moral Anak Usia Dini}

Gaya pengasuhan anak sebagai salah satu strategi mendidik oleh orang tua yang berkontribusi pada perkembangan anak selanjutnya. Hal ini sudah dikaji sebelumnya dalam penelitian yang dilakukan oleh Walker \& Hennig (2010). Hasil penelitian tersebut menunjukan bahwa gaya pengasuhan yang melibatkan interaksi antara orang tua dan anak dapat memprediksi perkembangan moral anak-anak selanjutnya. Gaya pengasuhan tersebut terbagi menjadi tiga gaya pengasuhan. Sedangkan Ditha Prasanti \& Dinda Rakhma Fitriani, (2018) mengemukakan bahwa pola asuh terkait dengan penanaman karakter yang dilakukan dengan menceritakan tokoh pada sebuah cerita yang dijadikan sebagai teladan. 
Tabel 1. Gaya Pengasuhan Orang Tua

\begin{tabular}{lll}
\hline No & Gaya pengasuhan & \multicolumn{1}{c}{ Keterangan } \\
\hline 1. & Otoriter & $\begin{array}{l}\text { Orang tua yang menampilkan interaksi yang sangat operasional dan } \\
\text { informatif }\end{array}$ \\
2. & Permisif & $\begin{array}{l}\text { Orang tua dengan interaksi informatif yang melibatkan berbagi informasi } \\
\text { dan memberikan perspektif sederhana } \\
\text { Orang tua mengontrol perilaku anak untuk menyesuaikan diri dengan } \\
\text { standar yang diharapkan }\end{array}$ \\
\hline
\end{tabular}

Pertama ditandai oleh orang tua yang menampilkan interaksi yang sangat operasional, sedangkan yang kedua ditandai oleh orang tua yang menampilkan sesuatu dengan sangat informatif. Jika disimpulkan anak-anak yang diberikan pengertian secara kaku dengan melakukan sesuatu harus begini atau harus begitu, ini dapat dikategorikan kedalam pengasuhan yang otoriter. Orang tua menginginkannya anak-anak menerima apa pun yang mereka katakan tanpa menjelaskan mengapa perilaku tertentu harus dilakukan dihindari. Mereka ingin anak-anak mereka mengikuti mereka tanpa ragu. Prinsip tertentu harus diikuti hanya karena mereka disuruh melakukannya. Anak-anak di bawah gaya pengasuhan seperti ini mungkin menunjukkan keunggulan dalam kinerja mereka untuk waktu yang singkat tetapi di tahun-tahun kemudian rentan terhadap masalah penyesuaian, kecemasan, pembangkangan, perilaku agresif, depresi, rasa tidak aman, anti-sosial, kurang percaya diri, dll (Hazra \& Mittal, 2018). Dampak pengasuhan yang ditimbulkan dapat mengganggu kognitif dan interaksi kontekstual anak, dimana anak yang memiliki tingkat penalaran moral yang berbeda dengan orang dewasa, memproses sesuatu dengan kekuatanya sendiri dan pengetahuan dasarnya yang kemudian dapat timbul konflik kognitif tingkat tinggi yang menganggap sesuatu sebagai kritik antagonistik dan membuat anak bersikap defensif.

Selanjutnya, orang tua dengan interaksi informatif yang melibatkan berbagi informasi dan memberikan perspektif sederhana dalam konteks moral dimana masa kanakkanak dianggap sebagai masa pembelajaran kemakluman kesalahan dengan demikian tidak membantu anak membangun penalaran moral yang baik. Hal ini dapat dikaitkan dengan pengasuhan orang tua yang permisif. Kebanyakan orang tua menerapkan pola asuh permisif untuk mendidik yang didasari atas rasa kasihan yang berlebihan terhadap anak sehingga anak-anak cenderung bergantung pada orang tua (Nasution \& Maulana, 2020). Moral perlu dibangun dengan baik dan benar sejak awal apa yang benar seharusnya tetap diberitahukan bahwa itu benar dan apa yang salah sejak awal seharusnya tetap diberitahukan bahwa itu tidak benar, walaupun penalaran anak belum atau sampai pada tahapan yang lebih tinggi. Pemberian kebebasan lebih dari oleh orang tua yang terlalu penuh kasih sayang sering menyebabkan anak menjadi impulsif, tidak patuh, memberontak, lebih menuntut, tingkat ketergantungan yang tinggi, tugas yang berkurang, akademis yang buruk prestasi dan perilaku anti sosial (Steinberg, Blatt-Eisengart, \& Cauffman, 2006). Hapsari (2016) dalam (Nauli, Karnadi, \& Meilani, 2019) memaparkan anak belajar mengenai salah dan benar dimulai dari hal-hal sederhana dalam kehidupan sehari-sehari. Ketika anak melakukan kesalahan, sebaiknya segera diberi penjelasan kenapa hal yang dilakukannya salah atau sebaliknya ketika anak melakukan hal yang benar, segera beritahu alasan kenapa anak benar melakukannya. Hal ini akan membantu mengembangkan konsep moralnya. Ini sebagai salah satu hal yang membentuk moral kebiasaan anak yang akan berlajut dikemudian hari agar tidak menjadi individu yang lenggang atau terlalu luwes dalam kesalahan dan memandang enteng sebuah kesalahan karena didikan yang salah sejak awal.

Sementara itu, orang tua dengan interaksi yang mendukung dengan anak, seperti humor ringan, pujian, dorongan untuk berpartisipasi dan mendengarkan tanggapan, membuat aturan dengan nada positif untuk diskusi atau membuat kesepakatan dan untuk memperbaiki sebuah hubungan, dapat menumbuhkan moral yang lebih baik terhadap anak. 
Gaya pengasuhan anak ini dipandang paling kondusif perkembangan anak-anak dimana orang tua suportif terhadap anak (demokratis). Pola asuh yang seperti ini ditandai dengan kontrol perilaku anak untuk menyesuaikan diri dengan standar yang diharapkan. Orang tua yang berwibawa, mempraktikkan kontrol untuk membentuk anak-anak dengan menjelaskan alasan praktik dengan tanpa merusak kepribadian mereka (Karmakar, 2015). Pola asuh demokratis menggunakan interaksi dua arah, dengan kedudukan orang tua dan anak dalam interaksi sejajar atau sama, pengambilan keputusan atas kesepakatan bersama dengan mempertimbangkan (keuntungan) antara orang tua dan anak, sehingga anak diberi kebebasan yang bertanggung jawab (Jamiatul, Maghfiroh, \& Astuti, 2020). Dalam hasil studi yang dilakukan (Rossman \& Rea, 2005) mengemukakan kontribusi gaya pengasuhan, yaitu pengasuhan otoritatif akan mengarah pada adaptasi anak yang lebih baik dan masalah eksternalisasi seperti kurang agresif, pengasuhan otoriter yang kuat mengarah pada anak dengan pembelajaran yang lebih tinggi dan membuat masalah, dan pengasuhan permisif mengarah pada kekhawatiran yang lebih tinggi dan masalah internalisasi seperti depresi dan penarikan sosial.

Selanjutnya, dalam studi Juharta, Tjalla, \& Hidayat (2015) memaparkan pola asuh demokratis atau otoritatif dapat menimbulkan komunikasi serta hubungan yang harmonis antara anak dan orang tua, anak yang dengan pengasuhan otoritatif lebih percaya diri, baik, mandiri dan mampu untuk mengungkapkan apa yang dirasakan (Nasution \& Maulana, 2020). Sementara itu, Juharta dkk. (2015) memaparkan pengasuhan dengan pola asuh otoriter membuat anak cenderung tidak mampu untuk mengeluarkan pendapatnya, anak mengalami kesulitan dalam bersosialisasi dan berkomunikasi dengan orang lain, sementara dengan pola asuh permisif anak cenderung akan sulit untuk bersosialisai dengan lingkungannya yang merupakan kebutuhan bagi anak itu sendiri. Selanjutnya anak juga dapat memiliki kepatuhan langsung ketika orang tua menggunakan pengsuhan keras (Benjet \& Kazdin, 2003). Orang tua memiliki kesempatan yang luas untuk mempengaruhi anak-anak pada tahun-tahun awal perkembanganya, adanya kesempatan untuk selalu mendorong dan memfasilitasi pembangunan moral anak secara keseluruhan atau utuh. Selain itu, orang tua memiliki kekuatan untuk membantu anak-anak untuk mengidentifikasi serta mengadopsi karakteristik hal-hal yang positif, karena orang tua bertanggung jawab menanamkan aspek-aspek moralitas dalam diri anak yang dilakukan melalui pengasuhan. Berbagai karakteristik moralitas yang akan diinternalisasi dalam diri anak, seperti pengendalian diri, empati, hati nurani, kepatuhan, orientasi sosial, harga diri, penalaran moral, dan altruisme tidak terlepas dari peran orang tua di dalamnya (Berkowitz \& Grych, 1998).

\section{Pengasuhan Keras Orang Tua dan Pelepasan Moral}

Orang tua selalu ingin anaknya menjadi seseorang yang baik, termasuk menginginkan anaknya patuh dan disiplin. Segala upaya pastinya dilakukan orang tua untuk dapat menjadikan anaknya menjadi seseorang yang bermoral, termasuk dengan kekerasan. Pengasuhan keras memiliki dampak negatif walaupun tetap memiliki dampak yang positif, salah satnya adalah pelepasan moral pada perkembangan selanjutnya, dimana anak mampu berperilaku tidak etis tanpa mengkhawatirkan konsekuensi yang akan ditanggung. Hal ini sebelumnya pernah dikaji oleh (Qi, 2019) dengan hasil yang menunjukkan bahwa pengasuhan yang keras secara langsung dan tidak langsung dapat menyebabkan agresi anak dan pelepasan moral di masa selanjutnya. Pengasuhan dengan kekerasan tidak terbatas pada kekerasan fisik (memukul dengan tangan maupun benda) tetapi juga pada kekerasan verbal (mengumpat, mengolok, mencaci, dll).

Ada banyak konsensus tentang efek berbahaya dari bentuk-bentuk kekerasan terhadap anak termasuk kekerasan verbal atau hukuman fisik (MacMillan \& Mikton, 2017). Efek dari pengasuhan yang keras juga mendukung pembelajaran sosial Bandura dengan teori yang menyatakan dimana orang tua yang mendukung taktik disiplin yang keras dapat 
bertindak sebagai model perilaku agresif akan mengulang pengasuhan anak yang keras dapat membuat anak-anak secara bertahap menerima agresi dan melatih mereka untuk mencapai tujuan pribadi yang berharga dengan cara agresif. Efek langsung dari pengasuhan keras yang berkelanjutan yaitu timbulnya perilaku agresi anak. Beberapa kasus mengenai pengasuhan keras menemukan hubungan yang lebih kuat bahwa pengasuhan keras menimbulkan anak agresi bersamaan (Berthelon dkk., 2020).

Kemudian, efek tidak langsung akibat pengasuhan keras dengan jangka lama yaitu anak menunjukkan pelepasan moral pada masa selanjutnya. Pemaparan dan pemodelan dalam konteks tertentu oleh orang tua termasuk gaya pengasuhan keras dapat mempromosikan anak-anak untuk secara bertahap mengadopsi sikap dan kepercayaan yang akan memuculkan pelepasan moral (Hyde, Shaw, \& Moilanen, 2010). Dalam Augustine \& Stifter (2015) juga memaparkan hal serupa dimana perilaku pengasuhan anak memiliki efek yang berbeda ketika diterapkan dengan temperamen yang berbeda oleh orang tua. Berkaitan dengan hal tersebut, pada dasarnya pemahaman anak-anak tentang perilaku moral berasal dari pengalaman sosialisasi orang tua dan praktik pengasuhan anak dapat membentuk internalisasi aturan moral anak-anak (Kochanska, 2002).

Selanjutnya, masih terkait dengan kekerasan yang dialami oleh anak-anak dimana dapat memunculkan pelepasan moral. Dalam Thornberg, Wänström, Pozzoli, \& Hong (2019) Bandura dengan teori sosial kognitifnya memaparkan bahwa perubahan dalam pelepasan moral dan perilaku tidak bermoral merupakan proses yang bertahap dan timbal balik seiring berjalanya waktu. Jika diartikan, anak-anak yang menggertak orang lain secara bertahap merupakan tindakan untuk melepaskan diri dari perilaku serupa agar tidak berkelanjutan dikemudian hari. Pelaku intimidasi dengan demikian memprediksi pelepasan moral dari waktu ke waktu. Anak-anak sendiri dapat melepaskan diri dari sanksi-sanksi diri karena melakukan intimidasi, yang pada gilirannya memungkinkan mereka untuk meningkatkan perilaku intimidasi mereka di masa depan. Seperti yang diketahui bahwa terkadang ketika anak-anak melakukan kesalah ada kemakluman dalam tindakkan yang akhirnya dapat membuat mereka melakukan hal yang sama dimasa depan. Dalam hal ini, pelepasan moral memprediksi terjadinya intimidasi dari waktu ke waktu atau masa selanjutnya. Perkembangan seperti itu mungkin terjadi dimana berkelanjutanya seperti siklus antara pelepasan moral dan perilaku agresif, seperti yang paparkan dalam (Wang, Ryoo, Swearer, Turner, \& Goldberg, 2017).

Dari pemamparan yang ada, diketahui bahwa ketika kekerasan dalam bentuk apapun tetap akan menimbulkan efek dikemudian hari, dan hal tersebut kemungkinan akan berulang. Orang tua perlu dalam mempertimbangkan gaya pengasuhan yang diterapkan bagi anak mereka, karena pengasuhan dengan sebaik mungkin untuk anak diperlukan agar dapat membentuk anak menjadi pribadi yang lebih baik dikemudian hari termasuk dalam hal perkembangan moral.

\section{SIMPULAN}

Lingkungan keluarga merupakan lingkungan yang berkontribusi besar dalam perkembangan anak, dimana orang tua bertanggung jawab atas anaknya. Orang tua sebagai figur utama bagi anak, cara orang tua dalam membentuk anak dan membangun hubungan memiliki pengaruh dalam menginternalisasikan moral pada anak mereka. Gaya pengasuhan yang meliputi pengasuhan otoritatif atau demokrasi, otoriter, and permisif masing-masing memiliki dampak yang berbeda-beda dan akan dapat mempengaruhi perkembangan anak termasuk perekembangan moral di masa selanjutnya. Orang tua perlu mempertimbangkan gaya pengasuhan yang akan diterapkan bagi anak mereka, karena pengasuhan terbaik juga akan membawa dampak yang terbaik pula. 


\section{UCAPAN TERIMA KASIH}

Kami mengucapkan terima kasih kepada pihak-pihak yang sudah membantu dalam menyelesaikan artikel jurnal ini, semoga Allah SWT membalas dengah balasan yang paling baik. Aamiin.

\section{DAFTAR PUSTAKA}

Augustine, M. E., \& Stifter, C. A. (2015). Temperament, parenting, and moral development: Specificity of behavior and context. Social Development, 24(2), 285-303. https://doi.org/10.1111/sode.12092

Benjet, C., \& Kazdin, A. E. (2003). Spanking children: The controversies, findings, and new directions. Clinical Psychology Review, 23(2), 197-224. https://doi.org/10.1016/S02727358(02)00206-4

Berkowitz, M. W., \& Grych, J. H. (1998). Fostering goodness: Teaching parents to facilitate children's moral development. Journal of Moral Education, 27(3), 371-391. https://doi.org/10.1080/0305724980270307

Berthelon, M., Contreras, D., Kruger, D., Palma, M. I., Dalimonte-merckling, D., Williams, J. M., ... Rotheram-borus, M. J. (2020). Harsh parenting during early childhood and child development. Economics and Human Biology, 36(October 2018), 88-96. https://doi.org/10.1016/j.ehb.2019.100831

Bibi, F., Chaudhry, A. G., Awan, E. A., \& Tariq, B. (2013). Contribution of Parenting Style in life domain of Children. IOSR Journal of Humanities and Social Science, 12(2), 91-95. https:// doi.org/10.9790/0837-1229195

Campbell, W. C., Cavico, F. J., Pellet, P. F., \& Mujtaba, B. G. (2010). Applying Moral Development Literature And Ethical Theories To The Administration Of Taxes In Kosovo. International Business $\mathcal{E}$ Economics Research Journal (IBER), 9(7). https:/ / doi.org/10.19030/iber.v9i7.594

Ditha Prasanti, \& Dinda Rakhma Fitriani. (2018). Pembentukan Karakter Anak Usia Dini: Keluarga, Sekolah, Dan Komunitas. Program Studi Ilmu Komunikasi Fakultas Ilmu Komunikasi Universitas PadjadjaranProgram Studi Ilmu Komunikasi Fakultas Ilmu Komunikasi Universitas Gunadharma, 2(1), 13-19.

Ellemers, N., van der Toorn, J., Paunov, Y., \& van Leeuwen, T. (2019). The Psychology of Morality: A Review and Analysis of Empirical Studies Published From 1940 Through 2017. Personality and Social Psychology Review, 23(4), 332-366. https://doi.org/10.1177/1088868318811759

Grusec, J. E., Goodnow, J. J., \& Kuczynski, L. (2000). New Directions in Analyses of Parenting Contributions to Children's Acquisition of Values. 71(1), 205-211.

Hazra, S., \& Mittal, S. (2018). Role of Parenting in Moral Development: An Overview. International Journal of Indian Psychology, 6(2). https:/ / doi.org/10.25215/0602.057

Hyde, L. W., Shaw, D. S., \& Moilanen, K. L. (2010). Developmental precursors of Moral Disengagement and the role of Moral Disengagement in the development of antisocial behavior. Journal of Abnormal Child Psychology, 38(2), 197-209. https://doi.org/10.1007/s10802-009-9358-5

Jambon, M., \& Smetana, J. G. (2015). Moral Development, Theories of. (December), 0-28. https://doi.org/10.1016/B978-0-08-097086-8.23201-7

Jamiatul, J., Maghfiroh, M., \& Astuti, R. (2020). Pola Asuh Orang Tua dan Perkembangan Moral Anak Usia Dini (Studi Kasus di TK Al-Ghazali Jl. Raya Nyalaran Kelurahan Kolpajung Kecamatan Pamekasan Kabupaten Pamekasan). Kiddo: Jurnal Pendidikan Islam Anak Usia Dini, 1(1). https:/ / doi.org/10.19105/kiddo.v1i1.2973

Juharta, Y. nur fatimah, Tjalla, A., \& Hidayat, dede rahmat. (2015). Belajar Dilihat Dari Pola Asuh Authoritative , Authoritarian Dan Permisif. Insight Jurnal, 4(1), 1-8. https://doi.org/10.21009/INSIGHT.041.18

Karmakar, R. (2015). Does Parenting Style Influence the Internalization of Moral Values in 
DOI: 10.31004/obsesi.v5i1.550

Children and Adolescents? Psychological Studies, 60(4), 438-446. https://doi.org/10.1007/s12646-015-0338-2

Knudsen, E. I. (2004). Sensitive periods in the development of the brain and behavior. Journal of Cognitive Neuroscience, 16(8), 1412-1425. https:/ / doi.org/10.1162/0898929042304796

Kochanska, G. (2002). Committed compliance, moral self, and internalization: a mediational model. Developmental Psychology, 38(3), 339-351. https://doi.org/10.1037/00121649.38.3.339

MacMillan, H. L., \& Mikton, C. R. (2017). Moving research beyond the spanking debate. Child Abuse and Neglect, 71, 5-8. https:/ / doi.org/10.1016/j.chiabu.2017.02.012

Molchanov, S. V. (2013). The Moral Development in Childhood. Procedia - Social and Behavioral Sciences, 86, 615-620. https://doi.org/10.1016/j.sbspro.2013.08.623

Nasution, N., \& Maulana, I. (2020). Jurnal Obsesi : Jurnal Pendidikan Anak Usia Dini Analisis Pembelajaran Berhitung melalui Media Prisma Pintar pada Anak Usia Dini Abstrak. 4(1), 230-236. https:// doi.org/10.31004/obsesi.v4i1.311

Nauli, V. A., Karnadi, K., \& Meilani, S. M. (2019). Peran Ibu Pedagang Pasar 24 Jam Terhadap Perkembangan Moral Anak (Penelitian Studi Kasus di Kota Bekasi). Jurnal Obsesi: Jurnal Pendidikan Anak Usia Dini, 3(1), 241. https://doi.org/10.31004/obsesi.v3i1.179

Permendikbud No. 137. Standar Nasional Pendidikan Anak Usia Dini. , Peraturan Menteri Pendidikan Dan Kebudayaan Republik Indonesia § (2014).

Qi, W. (2019). Harsh parenting and child aggression: Child moral disengagement as the mediator and negative parental attribution as the moderator. Child Abuse and Neglect, 91(September 2018), 12-22. https:// doi.org/10.1016/j.chiabu.2019.02.007

Rossman, B. B. R., \& Rea, J. G. (2005). The relation of parenting styles and inconsistencies to adaptive functioning for children in conflictual and violent families. Journal of Family Violence, 20(5), 261-277. https:/ / doi.org/10.1007/s10896-005-6603-8

Steinberg, L., Blatt-Eisengart, I., \& Cauffman, E. (2006). Patterns of competence and adjustment among adolescents from authoritative, authoritarian, indulgent, and neglectful homes: A replication in a sample of serious juvenile offenders. Journal of Research on Adolescence, 16(1), 47-58. https://doi.org/10.1111/j.15327795.2006.00119.x

Thornberg, R., Wänström, L., Pozzoli, T., \& Hong, J. S. (2019). Moral Disengagement and School Bullying Perpetration in Middle Childhood: A Short-Term Longitudinal Study in Sweden. Journal of School Violence, 18(4), 585-596. https:/ / doi.org/10.1080/15388220.2019.1636383

Turiel, E. (2018). Moral Development in the Early Years: When and How. 94720, 297-308. https://doi.org/10.1159/000492805

Volling, B. L., Mahoney, A., \& Rauer, A. J. (2009). Sanctification of Parenting, Moral Socialization, and Young Children's Conscience Development. Psychology of Religion and Spirituality, 1(1), 53-68. https:// doi.org/10.1037/a0014958

Walker, L. J., \& Hennig, K. H. (2010). Parenting Style and the Development of Moral Reasoning. Journal of Moral Education, (December 2014), 37-41. https://doi.org/10.1080/030572499103133

Wandi, Z. N., \& Mayar, F. (2020). Jurnal Obsesi: Jurnal Pendidikan Anak Usia Dini Analisis Kemampuan Motorik Halus dan Kreativitas pada Anak Usia Dini melalui Kegiatan Kolase Abstrak. 4(1), 351-358. https://doi.org/10.31004/obsesi.v4i1.347

Wang, C., Ryoo, J. H., Swearer, S. M., Turner, R., \& Goldberg, T. S. (2017). Longitudinal Relationships between Bullying and Moral Disengagement among Adolescents. Journal of Youth and Adolescence, 46(6), 1304-1317. https://doi.org/10.1007/s10964016-0577-0 